\title{
HUBUNGAN MOBILISASI PADA MASA NIFAS DENGAN PENGELUARAN LOCHEA Di PRAKTEK MANDIRI BIDAN L.M PEMATANGSIANTAR
}

\author{
Kandace Sianipar \\ Dosen Prodi Kebidanan Pematangsiantar Poltekkes Kemenkes RI Medan
}

\begin{abstract}
Abstrak
Mobilisasi atau gerakan sesegera mungkin bisa mencegah aliran darah terhambat, dengan melakukan mobilisasi maka pengeluaran lochea akan meningkat, sehingga pembuluh darah yang ada di otot uterus akan terjepit. Penelitian ini bertujuan untuk mengetahui hubungan mobilisasi pada masa nifas dengan pengeluaran lochea. Jenis penelitian survey analitik dengan desain cross sectional. Lokasi penelitian di PMB L. M Pematangsiantar, sampel penelitian adalah Ibu masa nifas berjumlah 30 orang. Data yang digunakan adalah data primer dan sekunder yang diperoleh dari kuesioner. Hasil penelitian dianalisis dan disajikan dalam bentuk tabel. Pengolahan data dilakukan menggunakan program komputer. Berdasarkan penelitian ditemukan bahwa ibu postpartum 4 - 7 hari sebanyak 16 orang (53,3\%). Dan ibu yang melakukan mobilisasi dengan pengeluaran lochea lancar sebanyak 16 orang $(53,3 \%)$. Berdasarkan hasil uji chi-square menunjukkan ada hubungan mobilisasi pada masa nifas dengan pengeluaran lochea. Diharapkan kepada ibu untuk melakukan mobilisasi seusai 2 jam setelah melahirkan agar pengeluaran locheanya lancar, sehingga angka kematian ibu berkurang. Dan kepada tenaga kesehatan khususnya bidan agar memberikan penyuluhan tentang keuntungan dan kerugian dari mobilisasi.
\end{abstract}

Kata kunci : Masa Nifas, Mobilisasi, Pengeluaran Lochea

\section{PENDAHULUAN}

\section{Latar Belakang}

Menurut laporan Badan Kesehatan Dunia (WHO) mencatat bahwa angka ibu nifas meningkat tiap tahunnya. Pada tahun 2007 diperkirakan 60\% atau sekitar 598.000 dari jumlah tersebut sebanyak $40 \%$ ibu meninggal dunia ketika masa nifas terjadi dalam 24 jam pertama. Pada tahun 2009 ibu nifas sebanyak $80 \%$ atau sekitar 860.000 dan yang meninggal dunia sekitar 20\%. Tahun 2011 jumlah ibu nifas mengalami peningkatan $5 \%$ dari tahun sebelumnya atau sekitar 928.000 dengan angka kematian ibu nifas sebanyak 398.000 (wordpress.com).

Indonesia (2012) jumlah ibu nifas dalam beberapa tahun terakhir terlihat mengalami peningkatan sedangkan angka kematian ibu nifas mengalami penurunan. Pada tahun 2012 angka ibu nifas diperkirakan sebesar 96.000 dengan jumlah kematian sebanyak 12\%. Pada tahun 2010 sebanyak 125.000 ibu nifas dengan angka kematian sebanyak 7\%. Sedangkan pada tahun 2011 jumlah ibu nifas sebanyak 176.000 dengan angka kematian sebanyak 4\%. Sementara pada tahun 2012 enam bulan terakhir ibu nifas sebanyak 198.300 dengan angka kematian ibu sebanyak 3\% (wordpress.com).

Angka Kematian Ibu (AKI) di Sumatera Utara menunjukkan perbaikan dilihat dari tinggi rendahnya AKI merefleksikan status kesehatan / gizi ibu selama hamil dan nifas, kualitas pelayanan kesehatan serta kondisi lingkungan sosial dan ekonomi. Tahun 2012 AKI 290 per 100.000 kelahiran hidup menurun menjadi 260 per 100.000 kelahiran hidup pada tahun 2009 , dan provinsi
Sumatera utara terus berupaya mencapai target maksimal sebesar 226 per 100.000 kelahiran hidup (Dinkes Provsu, 2015).

Menurut hasil studi pendahuluan di Rumah Sakit RSUD Dr. H Soewondo Kendal data pada bulan Maret 2015 dengan jumlah pasien persalinan kurang lebih satu bulan rata-rata sekitar 69 pasien. Sebagai studi pendahuluan pada hari Rabu tanggal 2 Maret 2017 yang dilakukan kepada 9 ibu post partum dengan robekan perineum, $3(33,33 \%)$ orang ibu nifas telah mengetahui tentang pentingnya mobilisasi dini dan sudah melakukanya dari mulai meregangkan kaki, miring kanan kiri dan sudah dapat duduk disamping tempat tidur. Sisanya yaitu 6 $(66,67 \%)$ orang ibu nifas mengatakan, tidak mengetahui tentang pentingnya melakukan mobilisasi dini setelah melakukan persalinan sedangkan 4 diantara 6 ibu nifas tersebut telah melakukan mobilisasi dini atas saran dari bidan yang dinas dirumah sakit dan yang 2 orang ibu nifas takut untuk melakukan mobilisasi. Menurut informasi dari ibu nifas kebanyakan dari mereka masih mempercayai tentang mitos-mitos yang ada di masyarakat seperti: tidak boleh banyak bergerak karena melawan pantangan (Hamida, 2011).

Sesudah bersalin ibu tidak boleh berbaring terusmenurus. Walaupun letih dan masih merasakan sakit. Ibu dianjurkan mobilisasi seusai melahirkan, misalnya turun dari tempat tidur, belajar duduk, dan berjalan sendiri. Mobilisasi ini bertujuan agar sirkulasi darah menjadi baik, menghindari pembengkakan, dan mencegah thrombosis (Sinsin, 2008). 
Ibu yang melahirkan secara normal bisa melakukan mobilisasi 2 jam seusai bersalin dan 8 jam setelah bersalin untuk ibu yang menjalani ceasar. Ibu harus belajar menggerakkan persendian tubuh secara perlahan, bila ibu hanya berdiam diri pembulu darah dan otot - otot tubuh terutama daerah kaki dan panggul akan terganggu dan beresiko tersumbat bekuan darah (sinsin, 2008).

Umumnya para ibu pasca melahirkan takut melakukan banyak gerak. Ibu khawatir gerak - gerakan yang dilakukannya akan menimbulkan dampak yang tidak diinginkan. Padahal mobilisasi itu sangat penting bagi ibu nifas. Apabila ibu melakukan mobilisasi dini bisa memperlancar terjadinya involusi uteri (kembalinya rahim kebentuk semula) (Hamnah, 2008).

Menurut Kasdu (2003) jika tidak melakukan mobilisasi dini dapat mengakibatkan peningkatan suhu tubuh karena adanya involusi uterus yang tidak baik sehingga sisa darah tidak dapat dikeluarkan dan menyebabkan infeksi. Salah satu tanda infeksi adalah peningkatan suhu tubuh, perdarahan abnormal, dengan mobilisasi dini kontraksi uterus akan baik sehingga fundus uterus akan keras, maka resiko perdarahan abnormal dapat dihindarkan, karena kontraksi membentuk penyempitan pembuluh darah yang terbuka.

Mobilisasi dini tidak hanya mempercepat pengeluaran lochea tetapi juga bisa memulihkan kondisi tubuh ibu jika dilakukan dengan benar dan tepat, mobilisasi dini atau gerakan sesegera mungkin bisa mencegah aliran darah terhambat, dengan melakukan mobilisasi dini maka pengeluaran lochea akan meningkat, sehingga pembuluhpembuluh darah yang ada di otot-otot uterus akan terjepit (Purwati, 2011).

Data didapatkan pada tanggal 11 januari 2017 dari PMB L.M yaitu pada tahun 2014 terdapat 48 ibu nifas dengan bendungan ASI 8 ibu (16,7\%) dan tidak melakukan mobilisasi dini $10 \mathrm{ibu}(20,8 \%)$. Pada tahun 2015 terdapat 52 ibu nifas dengan bendungan ASI 6 ibu $(11,5 \%)$ dan tidak melakukan mobilisasi dini 7 ibu $(13,4 \%)$. Pada tahun 2016 terdapat $86 \mathrm{ibu}$ nifas dengan bendungan ASI $12 \mathrm{ibu}$ $(13,9 \%)$ dan tidak melakukan mobilisasi dini 9 ibu $(10,5 \%)$.

Berdasarkan survey pendahuluan yang peneliti lakukan di PMB L.M Pematangsiantar terdapat $30 \mathrm{ibu}$ pada masa nifas, setelah dilakukan wawancara kepada beberapa orang ibu pada masa nifas di PMB L.M Pematangsiantar ternyata $2 \mathrm{ibu}$ yang tidak melakukan mobilisasi dini . Berdasarkan uraian diatas peneliti tertarik untuk melakukan penelitian dengan judul "Hubungan Mobilisasi Pada Masa Nifas Dengan Pengeluaran Lochea Di PMB L.M Pematangsiantar.

\section{Rumusan Masalah}

Berdasarkan latar belakang masalah maka dapat dirumus tersebut penulis ingin melakukan penelitian tentang "Adakah Hubungan Mobilisasi pada masa nifas Dengan Pengeluaran Lochea Di PMB L. M Pematangsiantar"

\section{Tujuan Penelitian}

Untuk mengetahui Hubungan Mobilisasi Pada masa Nifas Dengan Pengeluaran Lochea Di PMB L.M. Pematangsiantar.

a. Untuk mengetahui distribusi frekuensi mobilisasi pada masa nifas bedasarkan hari masa nifas di PMB L.M Pematangsiantar

b. Untuk mengetahui distribusi frekuensi masa nifas berdasarkan mobilisasi di PMB L.M Pematangsiantar

c. Untuk mengetahui hubungan mobilisasi pada masa nifas dengan pengeluaran lochea di PMB L.M Pematangsiantar

\section{MANFAAT PENELITIAN}

1. Hasil penelitian ini di harapkan dapat menambah wawasan dan pengetahuan bagi ibu nifas di PMB L.M. Pematangsiantar

2. Hasil penelitian ini di harapkan dapat menjadi sarana Informasi tentang hubungan mobilisasi dini dengan pengeluaran lochea, sehingga dapat dijadikan langkah awal dalam membantu kebijakan pelayanan kebidanan.

3. Hasil penelitian ini di harapkan dapat menambah wawasan pengetahuan bagi peneliti dan sebagai masukan bagi peneliti lain.

\section{Kerangka Konsep}

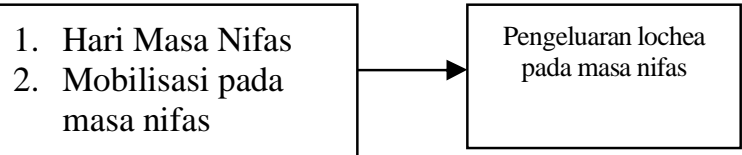

\section{Definisi Operasional}

\begin{tabular}{|c|c|c|c|c|c|}
\hline No & Variabel & Definisi Operasional & Alat Ukur & Kategori & Skala Ukur \\
\hline 1 & Hari masa nifas & $\begin{array}{l}\text { Hari masa nifas adalah hari } \\
\text { dimana ibu sudah selesai } \\
\text { melahirkan }\end{array}$ & Kuesioner & $\begin{array}{l}\text { Dikategorikan atas: } \\
\text { a. } 1-3 \text { hari post } \\
\text { partum } \\
\text { b. } 4-7 \text { hari post } \\
\text { partum }\end{array}$ & Ordinal \\
\hline
\end{tabular}

2 Mobilisasi pada Mobilisasi adalah pergerakan masa nifas awal yang dimulai dengan menggerakkan lengan, kaki, duduk secara perlahan, dan ibu sudah jalan sendiri

$\begin{array}{lll}\text { Kuesioner } & \text { Dikategorikan atas : } & \text { Nominal } \\ & \text { a. Melakukan } & \\ & \text { b. Tidak } & \\ & & \text { Melakukan }\end{array}$




\begin{tabular}{|c|c|c|c|c|c|}
\hline No & Variabel & Definisi Operasional & Alat Ukur & Kategori & Skala Ukur \\
\hline 3 & $\begin{array}{l}\text { Pengeluaran } \\
\text { lochea pada } \\
\text { masa nifas }\end{array}$ & $\begin{array}{l}\text { Lokhea adalah cairan yang } \\
\text { berbau amis (anyir), meskipun } \\
\text { tidak tidak terlalu menyengat dan } \\
\text { volumenya berbeda pada setiap } \\
\text { wanita }\end{array}$ & Kuesioner & $\begin{array}{cl}\text { Dikategorikan atas : } \\
\begin{array}{cl}\text { a. Lancar } \\
\text { b. } & \text { Tidak } \\
& \text { Lancar }\end{array}\end{array}$ & Nominal \\
\hline
\end{tabular}

\section{Hipotesis}

Hipotesis penelitian ini adalah Terdapat hubungan mobilisasi dini dengan pengeluaran lochea pada ibu nifas .

\section{Metode Penelitian}

Jenis penelitian adalah penelitian analitik yaitu untuk mengetahui hubungan mobilisasi dini pada masa nifas dengan pengeluaran lochea melaluai uji hipotesis, dengan rancangan penelitian cross sectional. Lokasi Penelitian di PMB L.M Jalan Kelapa Kuning No. 5 Pematangsiantar. Populasi dalam penelitian adalah seluruh ibu pada masa nifas yang ada di PMB L. M Pematangsiantar sebanyak $30 \mathrm{ibu}$ pada masa nifas dan keseluruhan populasi dijadikan objek penelitian. Metode pengumpulan data menggunakan data primer yaitu data yang dikumpulkan langsung dari responden melalui pengisian kuesioner yang menggunakan metode observasi. Instrumen dalam penelitian ini adalah kuesioner yang diisi oleh responden terdiri dari pertanyaan tentang mobilisasi dini dengan pengeluaran lochea. Pengukuran untuk Hubungan Mobilisasi pada Masa Nifas dengan Pengeluaran Lochea disusun soal yang berjumlah 13 soal dalam bentuk pernyataan ya dan tidak, yang dikategorikan sebagai berikut: Melakukan : 50\% - $100 \%$, Tidak melakukan : $0 \%-50 \%$

Apabila skor benar nilainya 1 dan apabila salah nilainya 0 dengan rumus

$\frac{\text { Jumlah soal yang benar }}{\text { Jumlah seluru soal }} \times 100$

(Hidayat,2007)

Analisa Data hasil penelitian akan digunakan untuk menguji penelitian yang menggunakan taraf signifikan $\alpha=$ 0,05 : Analisa Univariat untuk melakukan analisa pada seluruh variable, mengetahui distribusi frekuensi dan variabel yang di teliti yaitu jumlah anak, jarak kehamilan. Analisa Bivariat dilakukan terhadap 2 variabel yang diduga berhubungan atau korelasi yaitu apakah terdapat hubungan mobilisasi dini dengan pengeluaran lochea pada ibu nifas yang dilakukan uji statistik $\mathrm{x}$ dengan tingkat kepercayaan $\mathrm{n}$ $(\mathrm{x})=0,05$

Teknik analisa yang digunakan adalah Chi Square

$$
\frac{\mathrm{X}^{2}=\sum(\mathrm{Fo}-\mathrm{Fe})^{2}}{\mathrm{Fe}}
$$

Keterangan :

$\mathrm{X}^{2}=$ Harga Chi Square yang dihitung di bandingkan dengan Chi Square tabel.

Fo $=$ Frekuensi yang diselidiki (Observed)

$\mathrm{Fe}=$ Frekuensi yang dihatapkan $($ Experted $)$

Dari hasil perhitungan statistik akan diketahui ada tidaknya hubungan yang signifikasi melalui perbandingan antara veriabel yang diteliti dengan tingkat kepercayaan yang digunakan $\alpha=0.05$ artinya bila nilai Chi Square tabel maka tidak terdapat hubungan antara variabel bebas dengan variabel terikat.

\section{HASIL PENELITIAN}

Hasil penelitian yang dilakukan tentang Hubungan Mobilisasi Pada Masa Nifas Dengan Pengeluaran Lochea Di PMB L. M Pematangsiantar sebagai berikut :

1. Analisa Univariat

Tabel 4.1

Distribusi Frekuensi Mobilisasi Pada Masa Nifas Bedasarkan Hari Masa Nifas

\begin{tabular}{clcc}
\hline No. & \multicolumn{1}{c}{ Hari Masa Nifas } & f & \% \\
\hline 1. & $1-3$ hari post partum & 12 & 40 \\
2. & 4-7 hari post partum & 18 & 60 \\
\hline & Jumlah & 30 & 100 \\
\hline
\end{tabular}

Tabel 4.2

Distribusi Frekuensi Masa Nifas Berdasarkan Mobilisasi

\begin{tabular}{clcc}
\hline No. & \multicolumn{1}{c}{ Mobilisasi } & f & \% \\
\hline 1. & Melakukan & 18 & 60 \\
2. & Tidak melakukan & 12 & 40 \\
\hline & Jumlah & 30 & 100 \\
\hline
\end{tabular}

Tabel 4.3

Distribusi Frekuensi Masa Nifas Berdasarkan Pengeluaran Lochea

\begin{tabular}{cllc}
\hline No. & Pengeluaran Lochea & f & \% \\
\hline 1. & Lancar & 20 & 66,7 \\
2. & Tidak lancar & 10 & 33,3 \\
\hline & Jumlah & 30 & 100 \\
\hline
\end{tabular}

2. Analisa Bivariat

Untuk mengetahui ada tidaknya Hubungan Mobilisasi Pada Masa Nifas Dengan Pengeluaran Lochea Di PMB L. M Pematangsiantar dilakukan uji Chi-square.

Tabel 4.4

Tabel Kontingensi Mobilisasi Pada Masa Nifas Dengan Pengeluaran Lochea

\begin{tabular}{|c|c|c|c|c|c|c|}
\hline \multirow{3}{*}{ Hari masa nifas } & \multicolumn{4}{|c|}{ Pengeluaran lochea } & \multirow{2}{*}{ Total } & \multirow{3}{*}{$\mathbf{X}^{2}$} \\
\hline & \multicolumn{2}{|c|}{ Lancar } & \multicolumn{2}{|c|}{ Tidak lancar } & & \\
\hline & $\mathbf{f}$ & $\%$ & f & $\%$ & f $\%$ & \\
\hline $1-3$ hari & \multicolumn{2}{|c|}{413,3} & \multicolumn{2}{|c|}{826,7} & \multirow{2}{*}{\multicolumn{2}{|c|}{$\begin{array}{llll}12 & 40 & 10,000 & 0,002 \\
18 & 60 & & \end{array}$}} \\
\hline 4-7 hari & \multicolumn{2}{|c|}{1653,3} & \multicolumn{2}{|c|}{26,7} & & \\
\hline Total & \multicolumn{2}{|c|}{2066,7} & \multicolumn{2}{|c|}{1033,3} & \multicolumn{2}{|l|}{30100} \\
\hline Mobilisasi & $\mathbf{f}$ & $\%$ & $\mathbf{f}$ & $\%$ & f $\%$ & \\
\hline Melakukan & & 53,3 & & 5,7 & $18 \quad 60$ & $10,0000,002$ \\
\hline Tidak melakukan & & 13,3 & & 26,7 & 1240 & \\
\hline Total & & 66,7 & & 33,3 & 30100 & \\
\hline
\end{tabular}




\section{PEMBAHASAN}

Hasil penelitian didapatkan bahwa dari 16 responden $(53,3 \%)$ ibu yang melakukan mobilisasi pada masa nifas dengan pengeluaran lochea lancar dan 8 responden $(26,7 \%)$ ibu yang tidak melakukan mobilisasi pada masa nifas dengan pengeluaran lochea tidak lancar.

Setelah dilakukan uji chi-square mobilisasi pada masa nifas dengan pengeluaran lochea diperoleh hasil probabilitas $=0,002$ dengan tingkat kepercayaan $=0.05$ atau $\rho<\alpha$ maka $\mathrm{H}_{\mathrm{o}}$ ditolak dan Ha diterima, sehingga ada hubungan antara mobilisasi pada masa nifas dengan pengeluaran lochea.

Hasil penelitian ini sama dengan hasil penelitian Purwanti menunjukkan bahwa ibu yang melakukan mobilisasi dini (84\%), mengeluarkan lochea berjumlah cukup (78\%) di peroleh hasil $\rho=0,004$. Hasil uji chisquare menunjukkan bahwa terdapat hubungan mobilisasi dengan pengeluaran lochea dimana $\rho<\alpha$ maka $\mathrm{H}_{\mathrm{o}}$ ditolak dan Ha diterima, sehingga ada hubungan antara mobilisasi pada masa nifas dengan pengeluaran lochea.

Mobilisasi (Early ambulation) adalah kebijakan untuk selekas mungkin membimbing ibu keluar dari tempat tidur dan membimbing selekas mungkin berjalan (Syaifuddin, 2010).

Pada persalinan normal dan keadaan ibu normal, biasanya ibu diperbolehkan untuk mandi dan ke WC dengan bantuan orang lain, yaitu pada 1 atau 2 jam setelah persalinan. Sebelum waktu ini, ibu diminta untuk melakukan latihan pernafasan dalam, serta latihan tungkai yang sederhana dan belajar duduk serta mengayunkan tungkai ditepi tempat tidur (Bahiyatun, 2009).

Mobilsasi ini bertujuan agar sirkulasi darah menjadi baik, menghindari pembengkakan, dan mencegah thrombosis. Bila ibu hanya berdiam diri, pembuluh darah dan otot - otot tubuh terutama daerah kaki dan panggul akan terganggu dan beresiko memunculkan tersumbat bekuan darah. Salah satu bentuk mobilisasi seusai bersalin adalah senam nifas. Senam ini sangat bermanfaat untuk memperbaiki sirkulasi darah, otot panggul, otot perut, dan otot tungkai bawah (Sinsin, 2008).

Akibat dari involusi uteri, lapisan luar desidua yang mengelilingi plasenta yang akan menjadi nekrotik. Desidua yang mati akan keluar bersama dengan sisa cairan. Campuran antara darah dan desidua inilah yang dinamakan lochea. Lochea istilah untuk secret uterus yang keluar melalui vagina selama puerperium. Lochea mempunyai bau yang amis (anyir) meskipun tidak terlalu menyengat, dan volumenya berbeda - beda pada setiap wanita, lochea ini mengalami perubahan karena proses involusi. Umumnya jumlah lochea lebih sedikit bila wanita postpartum dalam posisi berbaring dari pada berdiri Hal ini terjadi akibat pembuangan di vagina bagian atas saat wanita dalam posisi berbaring dan kemudian akan mengalir keluar saat berdiri (Heryani, 2010).

Peneliti berasumsi mobilisasi atau pergerakan sesegera mungkin bisa mencegah aliran darah terhambat, mobilisasi ini dilakukan setelah 2 jam postpartum. Setelah melakukan mobilisasi maka pengeluaran lochea akan lancar, sehingga pembuluh - pembuluh darah yang ada di otot - otot uterus akan terjepit, penelitian ini sama dengan pendapat dari Bahiyatun, 2009 dan Sinsin, 2008. Maka dari 18 responden postpartum $4-7$ hari $(60 \%)$ terdapat 16 responden $(53,3 \%)$ yang melakukan mobilisasi dengan pengeluaran lochea lancar. Sehingga disimpulkan pengeluaran lochea yang tidak lancar jika ibu postpartum tidak melakukan mobilisasi dari pada ibu postpartum yang melakukan mobilisasi, penelitian ini sama dengan pendapat dari Heryani, 2010.

\section{Simpulan}

1. Distribusi frekuensi berdasarkan hari masa nifas lebih banyak ibu dengan post partum $4-7$ hari sebanyak 18 orang $(60 \%)$.

2. Distribusi frekuensi berdasarkan mobilisasi pada masa nifas ibu yang melakukan mobilisasi 18 orang $(60 \%)$

3. Distribusi frekuensi berdasarkan pengeluaran lochea ibu yang pengeluaran lochea lancar sebanyak $20 \mathrm{ibu}(66,7 \%)$

4. Hasil uji chi-square pada tingkat kepercayaan $\alpha=$ 0,05 diperoleh hasil bahwa terdapat hubungan antara mobilisasi dengan pengeluaran lochea.

\section{Saran}

1. Perlunya melakukan mobilisasi seusai 2 jam setelah melahirkan agar pengeluaran locheanya lancar, sehingga angka kematian ibu berkurang khususnya di wilayah kerja PMB L. M Pematangsiantar.

2. Perlunya pendekatan berkesinambungan meningkatkan upaya promotif berupa penyuluhan tentang keuntungan dan kerugian mobilisasi, agar morbiditas dan mortalitas ibu nifas dapat lebih rendah dari waktu sebelumnya.

\section{DAFTAR PUSTAKA}

Bahiyatun, 2009. Asuhan Kebidanan Nifas Normal. EGC, Jakarta

Carpenito,

2000

http://dewilestariyasa.blogspot.com/2012/09/mobili sasi.html Diakses pada tanggal 18 maret 2017

Dinkes Provsu, 2015. Profil Kesehatan Sumatera Utara 2015 [online] Available at: http://dinkes.go.id/profil/provsu.pdf diakses 20 Januari 2017

Gallagher, $C$, 2005. Pemulihan Pascaoperasi Caesar. Erlangga, Jajarta

Kasdu, 2003. KTI Keperawatan hubungan mobilisasi dini dengan pengeluaran lochea. http://www.google.com/url?sa=t\&rct=i\&q=\&esrc= s\&source $=$ web $\& c d=3 \&$ cad $=$ rja $\&$ uact $=8 \& v e d=0 \mathrm{C}$ DUQFjAC\&url=http\%3A\%2F\%2Fejournal.umm.a c.id\%2Findex.php $\% 2$ Fkeperawatan $\% 2$ Farticle $\% 2 \mathrm{~F}$ viewFile\%2F1050\%2F1133 umm scientific journ al.pdf\&ei=hXU7U6WaC8WWiAfqlYDQDA\&usg =AFQjCNERoJjNng3shw3jjJX37cmyjtq5Bw\&bv m=bv.63934634,d.aGc.pdf diakses 02 februari 2017

Muchtar, R, 2000. Sinopsis obstetri. jilid I dan II. Penerbit Kedokteran EGC, Jakarta 
Notoadmodjo, S, 2010. Ilmu Perilaku Kesehatan. PT Rineka Cipta, Jakarta

Purwanti, 2011, KTI

Hubungan+mobilisasi+pengeluaran+locheahttp://is jd.pdii.lipi.go.id/index.php/Search.html?act=tampil \&id $=65898 \& \mathrm{idc}=24$

Rukiyah, A, dkk, 2012. Asuhan Kebidanan III (Nifas). Trans Info Media, Jakarta, 2011. Asuhan Kebidanan III (Nifas). Trans Info Media, Jakarta

Saleha, $S$, 2009.

http://ilmugreen.blogspot.com/2012/06/prosesmasa-nifas.html diakses tanggal 15 maret 2017

Sinsin, I, 2008. Masa Kehamilan dan Persalinan. PT Elex Media Komputindo, Jakarta

Syaifuddin, 2010. Pelayanan Kesehatan Maternal Dan Neonatal. http://syaifuddin.blogspot.com.diakses tanggal 29 Januari 2017.
Yulianti, L , 2012. Asuhan Kebidanan III (Nifas). Trans Info Media, Jakarta

Wordpress.com, 2011, Badan Kesehatan Dunia (WHO). https: // www. google. $\mathrm{Com} / \# \mathrm{q}=$ Menurut+laporan+Badan+Kesehatan+Du nia+\%28WHO\%29+mencatat+bahwa+angka+ibu +nifas+meningkat+tiap+tahunnya.pdf diakses tanggal 20 Januari 2017

Wordpress.com, 2012. KTI Keperawatan Pengetahuan Ibu Nifas Tentang Perawatan Diri http : //ishaknur06. blogspot. Com / 2013 / 08 / kti-keperawatanpengetahuan-ibu-nifas.html.pdf diaksese 20 Januari 2017 